\title{
Determining prognosis in acute exacerbation of COPD
}

This article was published in the following Dove Press journal:

International Journal of COPD

31 January 2017

Number of times this article has been viewed
Yves Flattet ${ }^{\prime}$

Nicolas Garin ${ }^{1,2}$

Jacques Serratrice'

Arnaud Perrier'

Jérome Stirnemann'

Sebastian Carballo'

'Department of Internal Medicine, Service of General Internal Medicine, Geneva University Hospitals, Geneva, ${ }^{2}$ Service of Internal Medicine, Riviera Chablais Hospital, Monthey, Switzerland
Correspondence: Sebastian Carballo Department of Internal Medicine, Service of General Internal Medicine, Geneva University Hospitals, Rue GabriellePerret-Gentil 4, I2 I| Geneva |4, Switzerland

Tel +4I 223739216

Fax +4I 223729235

Email sebastian.carballo@hcuge.ch
Background: Acute exacerbations are the leading causes of hospitalization and mortality in patients with COPD. Prognostic tools for patients with chronic COPD exist, but there are scarce data regarding acute exacerbations. We aimed to identify the prognostic factors of death and readmission after exacerbation of COPD.

Methods: This was a retrospective study conducted in the Department of Internal Medicine of Geneva University Hospitals. All patients admitted to the hospital with a diagnosis of exacerbation of COPD between 2008 and 2011 were included. The studied variables included comorbidities, Global Initiative for Chronic Obstructive Lung Disease (GOLD) severity classification, and biological and clinical parameters. The main outcome was death or readmission during a 5-year follow-up. The secondary outcome was death. Survival analysis was performed (log-rank and Cox).

Results: We identified a total of 359 patients (195 men and 164 women, average age 72 years). During 5-year follow-up, 242 patients died or were hospitalized for the exacerbation of COPD. In multivariate analysis, age (hazard ratio [HR] 1.03, 95\% CI 1.02-1.05; $P<0.0001$ ), severity of airflow obstruction (forced expiratory volume in $1 \mathrm{~s}<30 \%$; HR 4.65, 95\% CI 1.42-15.1; $P=0.01$ ), diabetes (HR 1.47, 95\% CI 1.003-2.16; $P=0.048$ ), cancer (HR 2.79, 95\% CI 1.68-4.64; $P<0.0001$ ), creatinine (HR 1.003, 95\% CI 1.0004-1.006; $P=0.02$ ), and respiratory rate (HR 1.03, 95\% CI 1.003-1.05; $P=0.028$ ) on admission were significantly associated with the primary outcome. Age, cancer, and procalcitonin were significantly associated with the secondary outcome.

Conclusion: COPD remains of ominous prognosis, especially after exacerbation requiring hospitalization. Baseline pulmonary function remains the strongest predictor of mortality and new admission. Demographic factors, such as age and comorbidities and notably diabetes and cancer, are closely associated with the outcome of the patient. Respiratory rate at admission appears to be the most prognostic clinical parameter. A prospective validation is, however, still required to enable the identification of patients at higher risk of death or readmission.

Keywords: COPD, exacerbation, prognosis

\section{Introduction}

COPD is currently the fifth leading cause of death in the world. As a result of aging populations, the absence of prognosis-modifying treatments, and the decline in mortality in other chronic diseases, the prevalence of COPD is increasing and it is estimated that by 2020 it will be the third leading cause of death worldwide. ${ }^{1,2}$

COPD is a chronic disease, and its course is punctuated by acute exacerbations of respiratory impairment. These exacerbations are the leading causes of death or hospital admission for patients with COPD., Exacerbations and related hospitalizations also heavily impact the quality of life of affected people. ${ }^{5}$

Despite this, scarce data are available regarding prognosis after a severe exacerbation of COPD, ie, an exacerbation leading to hospitalization. ${ }^{6}$ Studies conducted 
specifically on exacerbations have had diverse results. ${ }^{4,7-12}$ As for existing prediction models, such as the body-mass index, degree of airflow obstruction, dyspnea, exercise capacity (BODE) score, these are established for patients with stable disease. ${ }^{6,13}$

Two reviews have summarized the available evidence concerning the predictors of mortality and readmission after severe exacerbation of COPD. ${ }^{14,15}$ Both reviews identified three types of parameters, namely markers of severity of acute illness (eg, confusion, $\mathrm{pH}$, and $\mathrm{PaO}_{2}$ at admission), markers of underlying disease severity or comorbidities (eg, forced expiratory volume in $1 \mathrm{~s}\left[\mathrm{FEV}_{1}\right]$, and cardiac, and kidney disease), and factors relating to the quality of life and functional impairments. Parameters in these three categories are differentially associated with given clinical end points, separated into in-hospital mortality, mortality after discharge, and hospital readmission.

Identifying patients at high risk of death or readmission during an episode of severe exacerbation of COPD may enable more optimal use of available resources and help identify patients with very poor prognosis, in whom supportive care is perhaps more appropriate and useful. This study aimed at determining the factors associated with the risk of death and/or new admission up to 5 years after an initial hospitalization for an exacerbation of COPD.

\section{Methods}

\section{Design and population}

This was a retrospective study conducted in the Department of Internal Medicine of Geneva University Hospitals. All patients admitted to the hospital with a diagnosis of exacerbation of COPD between 2008 and 2011 were included. Patients leaving the hospital alive after a hospitalization with a principal diagnosis of an exacerbation of COPD according to the 10th revision of the International Classification of Diseases (ICD-10) (J44.0: COPD with acute exacerbation unspecified and J44.1: COPD with acute lower respiratory tract infections) were identified in the hospital electronic database. We excluded patients who were $<40$ years old at admission and those admitted for acute heart failure or asthma based on medical records. Patients who were directly transferred to another hospital or treated as outpatients were not included.

\section{Data collection and follow-up}

Relevant demographical, clinical, and biological parameters were obtained through both automated and manual extraction of data. Comorbidities frequently found in patients with COPD (high blood pressure, diabetes, dyslipidemia, heart failure, coronary artery disease, atrial fibrillation, acute and chronic renal failure, cancer, osteoporosis, stroke, and degenerative disease of the central nervous system) were extracted from the hospital electronic database using the ICD-10 classification of diseases. Blood test results (hemoglobin, leukocyte, thrombocyte counts, creatinine, sodium, potassium, C-reactive protein, procalcitonin, albumin, urea, arterial partial pressure of oxygen $\left[\mathrm{PaO}_{2}\right]$ and partial pressure of carbon dioxide $\left[\mathrm{PaCO}_{2}\right]$, bicarbonate, and $\mathrm{pH}$ ) were also extracted from the same database. We obtained both the first and the last available values during the index hospitalization. Transfer to the intensive care unit and medications prescribed at admission and discharge were also obtained. The first and the last vital sign parameters (heart rate, blood pressure, respiratory rate, temperature, and weight and body mass index) were manually recorded. We also documented the severity of airway obstruction measured with lung function test obtained when patients were stable; when multiple values were available, those obtained closest to the index hospitalization were used. The severity of airway obstruction was categorized according to the Global Initiative for Chronic Obstructive Lung Disease (GOLD) classification using spirometry values (stage I: $\mathrm{FEV}_{1}>80 \%$; stage II: $\mathrm{FEV}_{1}$ 50\%-80\%; stage III: $\mathrm{FEV}_{1} 30 \%-50 \%$; and stage IV: $\mathrm{FEV}_{1}<30 \%$ of predicted values). ${ }^{2}$

Follow-up extended until 60 months ( 5 years) after the initial hospital admission. Vital status was determined by consulting the medical files and the civil status database of the State of Geneva. Readmissions were tracked using the electronic database of the Geneva University Hospitals, the main public hospital in the Geneva region. Patients were considered to be alive if there was no indication of death within the hospital or in the civil status database.

\section{Outcomes}

The primary composite endpoint was death or readmission from the first day of hospitalization until 60 months. The secondary outcome was death from the first day of hospitalization until 60 months.

\section{Statistical analysis}

All categorical variables were expressed as numbers or percentages and were compared using Fisher's exact tests or univariate Cox model. All continuous variables were expressed using median, minimum-maximum ranges, and were compared using Wilcoxon test or univariate Cox model. All factors with a $P$-value of $<0.05$ following a univariate analysis were included in the multivariate analysis. Variables were selected using the backward step elimination. Prognostic factors were determined using the Cox regression 
analysis. Hazard ratios (HRs) were calculated with their $95 \%$ CIs. All tests were two sided with a 0.05 significance level. Analyses were performed using the R statistical software, Version 3.1.1.

\section{Multiple imputation}

When a Cox proportional hazards model is performed, the missing covariate data complicate the analysis and can undermine the certainty of effect sizes. ${ }^{16}$ Imputing the missing data uses all the data and can be performed using accessible methods, such as multiple imputation, where each missing value is replaced with a set of $m(>1)$ independent values to give $m$ separate complete datasets. This incorporates uncertainty of the missing data that cannot be achieved with single imputation $(m=1) .{ }^{17}$ There are many different techniques for performing multiple imputation, but the application of predictive mean matching after regression switching (MICEPMM) appears to be the best method when $>10 \%$ of data are missing. ${ }^{18}$
In a sensitivity analysis, we performed analysis with imputing data with MICE-PMM method, using "pmm" function $(m=10)$ in the "mice v2.22" package of R. ${ }^{18} \mathrm{New}$ multivariate analysis was performed for the primary outcome with model determined with actual data, and new backward selection model was performed with imputed data.

\section{Ethics committee approval}

The ethics committee of Geneva University Hospitals approved this study and waived the need for written informed consent from all participants because this was a retrospective study with anonymized patient data.

\section{Results}

\section{Patients}

A total of 359 patients met the inclusion criteria (195 men and 164 women). The characteristics of the patients are listed in Table 1. The median age was 74 (41-96) years, and most patients had multiple comorbidities. Of the 359 patients,

Table I Baseline characteristics for total population and for each group of the primary outcome with non-adjusted hazard ratio

\begin{tabular}{|c|c|c|c|c|c|c|c|}
\hline & \multicolumn{2}{|c|}{ Total population } & \multicolumn{2}{|c|}{$\begin{array}{l}\text { Death or } \\
\text { readmission (242) }\end{array}$} & \multicolumn{2}{|c|}{$\begin{array}{l}\text { No death/ } \\
\text { readmission (I I 7) }\end{array}$} & \multirow[t]{2}{*}{$\begin{array}{l}\text { Nonadjusted hazard } \\
\text { ratio }(95 \% \mathrm{Cl})\end{array}$} \\
\hline & $\mathbf{n}$ & Characteristics & n & Characteristics & $\mathbf{n}$ & Characteristics & \\
\hline Age, median (range) & 359 & $74(4 I-96)$ & 242 & $75(4 I-96)$ & 117 & $69(46-91)$ & $1.026(1.01-1.04)$ \\
\hline Male gender (\%) & 359 & $195(54)$ & 242 & 55.4 & 117 & 52.1 & $\mathrm{I} .12(0.8 \mathrm{I}-\mathrm{I} .53)$ \\
\hline \multicolumn{8}{|l|}{ Comorbidities } \\
\hline High blood pressure, n (\%) & 359 & $20 \mathrm{I}(56)$ & 242 & $136(56)$ & 117 & $65(56)$ & $0.98(0.76-1.27)$ \\
\hline Diabetes, n (\%) & 359 & $65(18)$ & 242 & $49(20)$ & 117 & $16(14)$ & $1.61(1.17-2.20)$ \\
\hline Dyslipidemia, n (\%) & 359 & $108(30)$ & 242 & $76(31)$ & 117 & $32(27)$ & $\mathrm{I} .07(0.82-\mid .4 \mathrm{I})$ \\
\hline Coronary artery disease, n (\%) & 359 & $75(21)$ & 242 & $55(23)$ & 117 & $20(17)$ & $1.49(1.10-2.02)$ \\
\hline Atrial fibrillation, n (\%) & 359 & $54(15)$ & 242 & $42(17)$ & 117 & $12(10)$ & $1.41(1.016-1.98)$ \\
\hline Heart failure, n (\%) & 359 & $66(18)$ & 242 & $53(22)$ & 117 & $13(1 \mid)$ & $1.54(1.14-2.1)$ \\
\hline Stroke, n (\%) & 359 & $18(5)$ & 242 & $15(6)$ & 117 & $3(3)$ & $1.62(0.96-2.74)$ \\
\hline Acute/chronic renal failure, n (\%) & 359 & $74(21)$ & 242 & $54(22)$ & 117 & $20(17)$ & $1.46(1.08-1.99)$ \\
\hline Cancer, n (\%) & 359 & $26(7)$ & 242 & $22(9)$ & 117 & $4(3)$ & $1.73(1.11-2.69)$ \\
\hline Pulmonary cancer, n (\%) & 359 & $17(5)$ & 242 & $13(5)$ & 117 & $4(3)$ & $1.62(0.92-2.84)$ \\
\hline Osteoporosis, n (\%) & 359 & $47(13)$ & 242 & $36(15)$ & 117 & II (9) & $1.24(0.87-1.77)$ \\
\hline Active smokers, n (\%) & 358 & $165(46)$ & 242 & $107(44)$ & 116 & $58(50)$ & $1.02(0.6 \mathrm{I}-\mathrm{I} .70)$ \\
\hline \multicolumn{8}{|l|}{ Pulmonary function } \\
\hline Mild or moderate COPD (FEV, $\geq 50 \%), n(\%)$ & 306 & $93(30)$ & 220 & $57(26)$ & 86 & $36(4 I)$ & $0.63(0.47-0.86)$ \\
\hline \multicolumn{8}{|l|}{ Vital parameters at admission } \\
\hline Heart rate (beats per min), median (range) & 335 & $98(54-220)$ & 223 & $100(54-200)$ & 112 & $93(59-151)$ & $1.008(1.002-1.014)$ \\
\hline Respiratory rate (I/min), median (range) & 322 & $24(I I-50)$ & 215 & $26(I I-50)$ & 107 & $22(11-42)$ & $1.03(1.01-1.05)$ \\
\hline Weight (kg), median (range) & 328 & $65(28-138)$ & 221 & $64(36-138)$ & 107 & $67(28-124)$ & $0.99(0.98-0.99)$ \\
\hline \multicolumn{8}{|l|}{ Laboratories values (at admission) } \\
\hline Hemoglobin level (g/L), median (range) & 357 & $137(7|-2| 0)$ & 242 & $136(7|-2| 0)$ & 115 & $14 \mid(84-197)$ & $0.09(0.98-0.99)$ \\
\hline Creatinine (g/L), median (range) & 358 & $76(35-905)$ & 242 & $77(36-905)$ & 116 & $73(35-318)$ & $1.003(1.001-1.004)$ \\
\hline Potassium (mmol/L), median (range) & 355 & $4.1(3-6.8)$ & 240 & $4.1(3-6.8)$ & 115 & $4(3-6.2)$ & $1.50(1.20-1.87)$ \\
\hline Albumin (g/L), median (range) & 174 & $31(16-40)$ & 127 & $31(16-40)$ & 47 & $32(19-39)$ & $0.96(0.92-0.99)$ \\
\hline $\mathrm{PaCO}_{2}(\mathrm{kPa})$, median (range) & 318 & $5.64(2.66-17.5)$ & 216 & $5.78(2.66-17.5)$ & 102 & $5.12(3.37-9.45)$ & $1.11(1.032-1.2)$ \\
\hline $\mathrm{pH}$, median (range) & 318 & $7.41(6.98-7.63)$ & 216 & $7.41(6.98-7.54)$ & 102 & $7.41(7.26-7.63)$ & $0.09(0.01-0.59)$ \\
\hline Procalcitonin ( $\mu \mathrm{g} / \mathrm{L})$, median (range) & 184 & $0.11(0.02-240)$ & 128 & $0.12(0.03-240)$ & 56 & $0.1(0.02-2.35)$ & $1.006(0.99-1.013)$ \\
\hline
\end{tabular}

Notes: $n$ : number of available data. $P$-value in bold when $<0.05$. Range is minimum-maximum.

Abbreviations: $\mathrm{Cl}$, confidence interval; $\mathrm{FEV}_{1}$, forced expiratory volume in I s; $\mathrm{PaCO}_{2}$, partial pressure of carbon dioxide. 
165 patients were active smokers at the time of inclusion (46\%), 164 patients were former smokers (47\%), and 25 patients had no smoking history (7\%). Lung function tests were available for 306 patients, of whom 93 (30\%) patients had GOLD stage I or II disease and 213 (70\%) patients had GOLD stage III or IV disease. At admission, $82 \%$ of the patients were on $\beta 2$ agonist therapy, $67 \%$ on anticholinergic therapy, and $71 \%$ on inhaled corticosteroids. A total of 78 (22\%) patients were on long-term oxygen therapy.

\section{Primary outcome (death or readmission)}

During the 60 months of follow-up, 242 (67\%) patients died or were readmitted for an exacerbation of COPD. The median time for death or readmission was 20 (16-24) months. In Kaplan-Meier analysis, $40 \%$ of patients had died or had been readmitted for an exacerbation of COPD within 1 year (Figure 1).

On univariate analysis, 17 variables were significantly associated with the primary outcome (Table 1$)$. The presence of type II diabetes (HR 1.61 [1.17-2.20], $P=0.03$ ), ischemic heart disease (HR 1.49 [1.10-2.02], $P=0.0091$ ), atrial fibrillation (HR 1.41 [1.016-1.98], $P=0.0402$ ), heart failure (HR 1.54 [1.14-2.1], $P=0.0051$ ), renal failure (HR 1.46 [1.08-1.99], $P=0.0134$ ), cancer (HR 1.73 [1.11-2.69], $P=0.0138$ ), and age (HR 1.026 [1.013-1.039], $P<0.001)$ were associated with an increased risk of death or readmission.

With respect to blood tests, only values corresponding to the admission period were significantly associated with the outcome. Higher potassium (HR 1.50 [1.20-1.87], $P<0.001$ ), creatinine (1.003 [1.001-1.004], $P<0.001$ ), and $\mathrm{PaCO}_{2}$ (HR 1.11 [1.032-1.2], $P=0.0053$ ) were associated with a worse outcome, while higher hemoglobin (HR 0.091

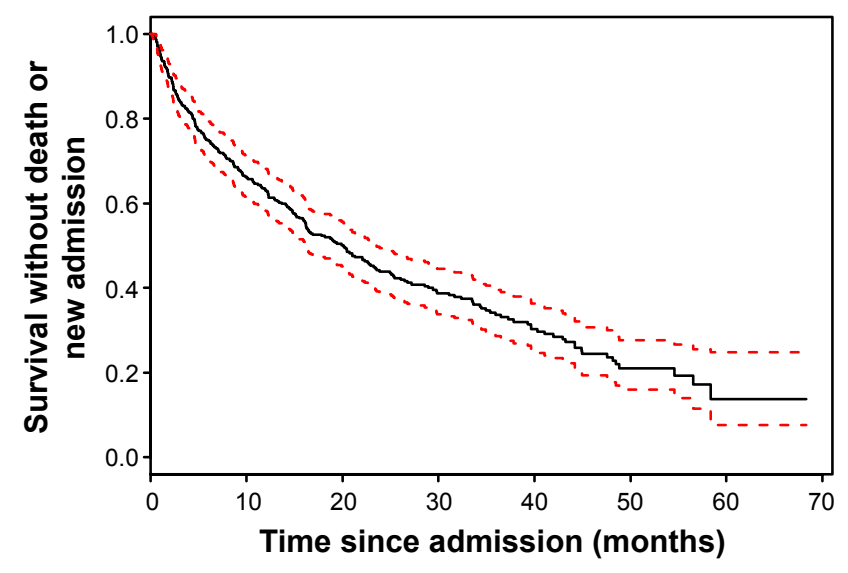

Figure I Kaplan-Meier curve of survival without death or new readmission (primary outcome) in patients with an exacerbation of COPD.

Note: $95 \% \mathrm{Cl}$ is in dashed lines.

Abbreviation: $\mathrm{Cl}$, confidence interval.
[0.985-0.997], $P=0.0064$ ), albumin (HR 0.96 [0.92-0.99], $P=0.0457$ ), and $\mathrm{pH}$ (HR 0.09 [0.01-0.59], $P=0.0119$ ) were associated with better outcome in univariate analysis.

Of the vital signs at admission, higher heart rate (HR 1.008 [1.002-1.014], $P=0.008$ ), higher respiratory rate (HR 1.03 [1.01-1.05], $P<0.001$ ), and lower weight (HR 0.99 [0.98-0.99], $P=0.0214$ ) were associated with a worse prognosis. Vital signs at discharge were not predictive of the outcome.

There were 269 complete data sets available for the principal analysis. Among these 269 patients, 191 died or were readmitted for an exacerbation of COPD during the follow-up. In the Cox proportional hazard model, age, GOLD stage, diabetes, cancer, creatinine, and respiratory rate were significantly associated with the outcome (Table 2).

The sensitivity analysis using the predictive mean matching to replace unavailable data included 359 patients and 242 events. Variables associated with the outcome in the main analysis remained significant in this sensitivity analysis (Table 3). However, two supplemental variables, which were weight and $\mathrm{PaCO}_{2}$, were associated with better outcome.

\section{Secondary outcomes}

During follow-up, 140 (39\%) patients had died. The median time for death was 50 (44- not available [NA]) months. The incidence of death in this COPD population was $18 / 100$ person-years.

On univariate analysis, several variables were associated with death $(P<0.05)$ (Table 4$)$, amongst which age (HR 1.055 [1.036-1.074]), the presence of type II diabetes (HR 1.56 [1.06-2.3]), ischemic heart disease (HR 1.60 [1.09-2.35]), atrial fibrillation (HR 1.86 [1.24-2.79]), renal failure (HR 1.80 [1.23-2.64]), cancer (HR 2.60 [1.58-4.26]), and pulmonary cancer (HR 2.67 [1.44-4.95]).

Table 2 Multivariate analysis for the primary outcome (death or readmission)

\begin{tabular}{|c|c|c|}
\hline Variables & Hazard ratio $(95 \% \mathrm{Cl})$ & $P$-value \\
\hline Age & $1.03(1.02-1.05)$ & $<\mathbf{0 . 0 0 0 I}$ \\
\hline Severity of COPD & Reference $\left(\mathrm{FEV}_{1} \geq 80 \%\right.$ ) & \\
\hline $50 \% \leq \mathrm{FEV},<80 \%$ & $2.17(0.67-7.05)$ & 0.20 \\
\hline $30 \% \leq \mathrm{FEV}_{1}<50 \%$ & $3.17(1.00-10.6)$ & 0.051 \\
\hline $\mathrm{FEV}_{1}<30 \%$ & $4.65(1.42-15.1)$ & 0.01 \\
\hline Diabetes II & $1.47(1.003-2.16)$ & 0.048 \\
\hline Cancer & $2.79(1.68-4.64)$ & $<\mathbf{0 . 0 0 0 I}$ \\
\hline Creatinine at admission $(\mu \mathrm{mol} / \mathrm{L})$ & $1.003(1.0004-1.006)$ & 0.02 \\
\hline Respiratory rate (at admission) & $1.03(1.003-1.05)$ & 0.028 \\
\hline
\end{tabular}

Notes: 269 patients analyzed, with 191 events ( 90 observations not included due to missing data). Values in bold indicate $P<0.05$.

Abbreviations: $\mathrm{Cl}$, confidence interval; $\mathrm{FEV}_{1}$, forced expiratory volume in I s. 
Table 3 Multivariate analysis for the primary outcome with predictive miss-matching data imputation

\begin{tabular}{|c|c|c|}
\hline Variables & Hazard ratio $(95 \% \mathrm{Cl})$ & $P$-value \\
\hline Age & $1.02(1.009-1.038)$ & 0.001 \\
\hline Severity of COPD & Reference $(\mathrm{FEV}, \geq 80 \%$ ) & \\
\hline $50 \% \leq \mathrm{FEV}_{1}<80 \%$ & $1.47(0.53-4.09)$ & 0.45 \\
\hline $30 \% \leq \mathrm{FEV},<50 \%$ & $2.06(0.75-5.66)$ & 0.15 \\
\hline $\mathrm{FEV}_{1}<30 \%$ & $2.65(0.94-7.49)$ & 0.06 \\
\hline Diabetes II & $1.80(1.28-2.54)$ & 0.0006 \\
\hline Cancer & $1.60(1.01-2.53)$ & 0.043 \\
\hline Creatinine at admission $(\mu \mathrm{mol} / \mathrm{L})$ & $1.03(1.005-1.05)$ & 0.01 \\
\hline $\mathrm{PaCO}_{2}$ at admission $(\mathrm{kPa})$ & I.II (I.02-I.20) & 0.007 \\
\hline Procalcitonin at admission $(\mu \mathrm{g} / \mathrm{L})$ & $1.005(0.99-1.01)$ & 0.17 \\
\hline Albumin at admission (mmol/L) & $0.97(0.94-1.003)$ & 0.08 \\
\hline $\begin{array}{l}\text { Blood pressure at } \\
\text { admission }(\mathrm{mmHg})\end{array}$ & $0.99(0.98-000 I)$ & 0.054 \\
\hline Respiratory rate at admission & $1.03(1.01-1.05)$ & 0.002 \\
\hline Weight at admission (kg) & $0.99(0.98-0.99)$ & 0.03 \\
\hline
\end{tabular}

Note: $P$-value in bold when $<0.05$.

Abbreviations: $\mathrm{Cl}$, confidence interval; $\mathrm{FEV}_{1}$, forced expiratory volume in I s; $\mathrm{PaCO}_{2}$, partial pressure of carbon dioxide.

Respiratory rate at admission was the only vital sign associated with higher risk of death (HR 1.029 [1.004-1.056]), and other vital signs at admission and at discharge were not associated with death. Lung function was not significantly associated with the secondary outcome.

With respect to biological parameters, three values at admission were significantly associated with a worse prognosis, such as higher creatinine (HR 1.003 [1.001-1.004]), higher potassium (HR 1.62 [1.20-2.19]), and higher procalcitonin (HR 1.009 [1.001-1.017]). While higher albumin level (HR 0.94 [0.89-0.98]) and higher hemoglobin level (HR 0.98 [0.97-0.99]) were associated with a better outcome.

There were 129 complete data sets available for the secondary analysis. Among them, 49 COPD patients died during the follow-up. In the Cox proportional hazard model, age (HR 1.12 [1.05-1.19]), cancer (HR 7.04 [2.22-22.36]), and procalcitonin (HR 1.02 [1.00-1.03]) were significantly associated with the outcome (Table 4).

On Kaplan-Meier analysis, survival for COPD patients after acute exacerbation was $\sim 85 \%$ after 1 year (Figure 2).

\section{Discussion}

Our study confirms the poor prognosis in terms of mortality and recurrent hospital admission after an acute exacerbation of COPD (Figure 1). To identify factors associated with this outcome, possible prognostic variables were categorized into comorbidities, vital signs at admission, and laboratory values. We observed that very few clinical and biological parameters are associated with the clinical outcome of patients, whereas comorbidities and lung function seem to be strongly associated with survival. As expected, cancer was a predictor of death.

Concerning lung function, our study is in line with previous observations that survival is inversely proportional to $\mathrm{FEV}_{1}$. Such results have been found in similar studies and are probably explained by the degree of ventilatory impairment and the higher risk of colonization by aggressive bacteria causing exacerbation. ${ }^{4,19,20}$ A study exploring the relationship between the degree of lung impairment and the bacterial flora of sputum in acute exacerbation demonstrated the higher prevalence of Pseudomonas aeruginosa and Hemophilus influenzae in the case of severe lung impairment. ${ }^{20}$

Not surprisingly, and as described in other studies, older patients present worse clinical outcomes after acute exacerbation. ${ }^{7,9,10,12}$ The impact of age on survival may be explained by a gradual and natural decline in lung function. Elderly patients also tend to have multiple comorbidities, making them more vulnerable to exacerbations. ${ }^{9,19}$ It is interesting to note that Groenewegen et $\mathrm{al}^{9}$ found similar results concerning the negative impact of age on survival, but younger age was associated with a higher risk for new exacerbation without a clear explanation.

With respect to comorbidities, surprisingly, cardiovascular disease, and in particular, ischemic heart disease, was not associated with outcome. This may reflect trends in improved treatment and decreased mortality of cardiovascular disease in general. Diabetes is a disease that is less described in COPD patients..$^{21,22}$ However, it has been shown in several studies that patients with obstructive spirometry tests showed an increased risk of developing diabetes. ${ }^{22-24}$ The link between diabetes and COPD is not clear, but systemic inflammation in COPD may be the promoter of diabetes. ${ }^{21,22}$ A further link may be the development of weakness of the respiratory muscles in a context of neuropathy. ${ }^{21}$ In terms of mortality, patients with COPD and diabetes also present a higher risk of cardiovascular death, but our study does not provide data on this aspect.

Cancer is another disease with a significant influence on the outcome of patients. We distinguished between lung cancer and other types of cancer. Indeed, COPD patients are known to be at higher risk for lung cancer, notably for squamous cell carcinoma, and cancer is described as the most frequent cause of death in patients with mild COPD.,25,26 Surprisingly, it was nonlung cancer that was associated with poor outcome. Influence of cancer alone is less studied in the case of exacerbation. ${ }^{7,27}$ Most studies include cancer in a set of other comorbidities using the Charlson index for their analysis. ${ }^{9} 10$ Nevertheless, this finding may be explained by 


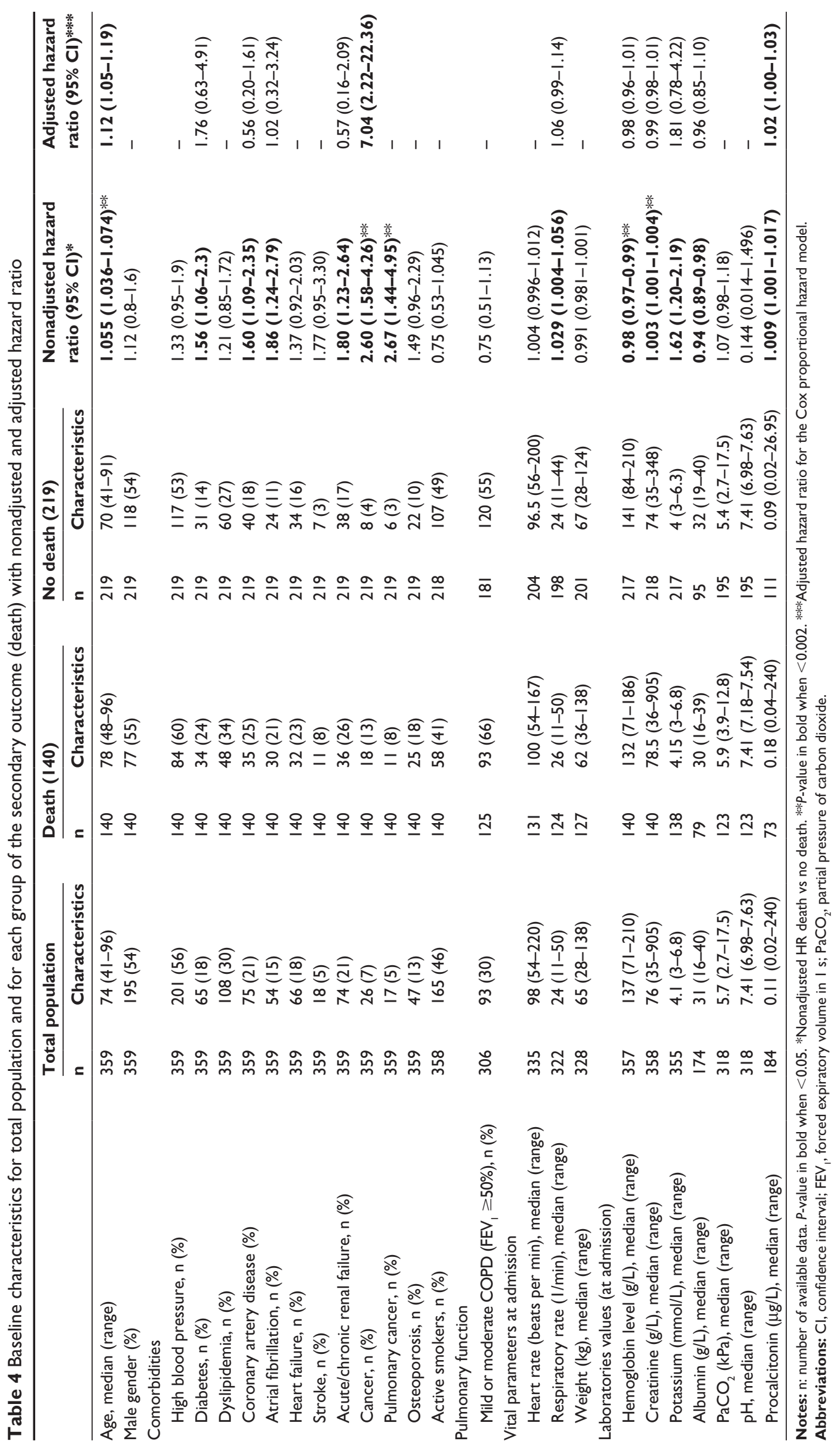




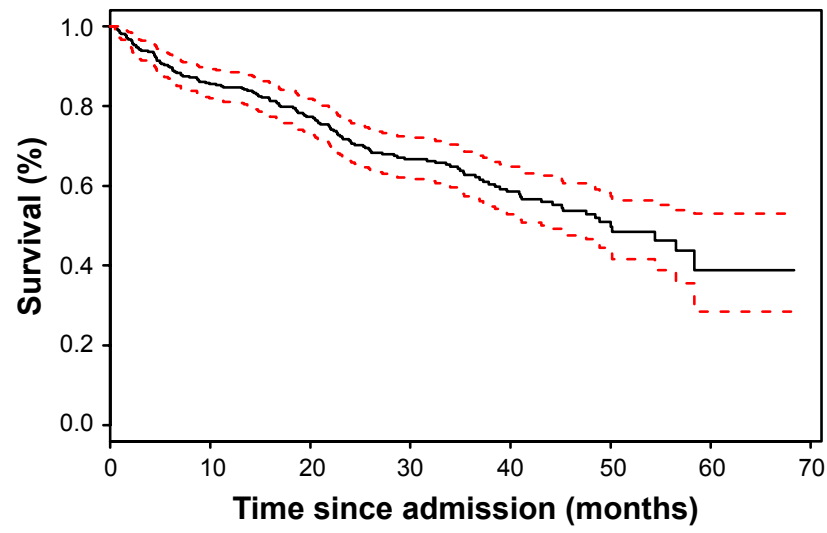

Figure 2 Kaplan-Meier curve of survival for COPD patients after acute exacerbation after I year.

Note: $95 \% \mathrm{Cl}$ is in dashed lines.

Abbreviation: $\mathrm{Cl}$, confidence interval.

the size of our study population and by the fact that whichever type of cancer is concerned, pulmonary or other, survival is significantly influenced by the natural evolution of the disease or side effects linked to treatment.

The only significant clinical parameter was the respiratory rate at admission. The risk of death or readmissions is increased in patients presenting severe tachypnea or dyspnea, elements already noted across different studies. Some other studies suggest that the degree of dyspnea is more predictive of mortality than $\mathrm{FEV}_{1}{ }^{28-30}$ Tachypnea has been consistently demonstrated as a marker of severity in multiple pathologies, perhaps because respiratory rate is at a crossroad of several physiopathological processes, such as respiratory failure, muscle function, and metabolic acidosis. ${ }^{31}$

With respect to laboratory values, only creatinine values and $\mathrm{PaCO}_{2}$ at admission were significantly associated with the primary outcome, with $\mathrm{PaCO}_{2}$ obtained from the multiple imputation analysis. $\mathrm{PaCO}_{2}$ is a reflection of alveolar ventilation, and there is a relationship between the blood gas analysis at admission and survival in acute exacerbation, with a worse prognosis in the case of high value of $\mathrm{PaCO}_{2}{ }^{8,9}$ Presumably, this is a reflection of the severity of the exacerbation. High values of creatinine were also associated with the risk of mortality or readmission. Impaired renal function is associated with poor outcome in most clinical settings.

Although albumin values may be of interest as a marker for patients' nutrition state, we found no association with the clinical outcomes. ${ }^{28,32}$ However, patients' weight analyzed through multiple imputation appears to play a protective role in the risk of death or readmissions during the exacerbation of COPD.

In certain clinical situations, procalcitonin is a useful marker for the diagnosis of bacterial infection, ${ }^{33}$ and some authors suggest that it should be measured in the exacerbations of COPD to help with the introduction of antibiotics. ${ }^{34}$ In this study, we found no association of procalcitonin values and the primary outcome. However, with respect to the secondary outcome, death, in addition to age and cancer, we found that elevated procalcitonin predicted a worse outcome. Procalcitonin is associated with worse outcomes in certain infectious diseases, such as pneumonia. ${ }^{35}$ However, its impact on long-term outcomes in COPD is surprising and remains to be confirmed in a larger study. The nonsystematic measurement in the emergency department meant that this information was often missing and makes correct interpretation difficult.

The sensitivity analysis from the multiple imputation confirmed the findings mentioned previously (age, severity of COPD, diabetes, cancer, creatinine, and respiratory rate). In addition, this analysis suggests that $\mathrm{PaCO}_{2}$ at admission is associated with the primary outcome. Presumably, this is a reflection of the severity of the exacerbation. Increase in weight was associated with a better outcome, and this is in line with previous findings.

With respect to mortality, three predictors were significant in the multivariate analysis, which were age, cancer, and procalcitonin. Other comorbidities and severity of lung function impairment were not significant. Age and cancer are expected factors, and procalcitonin was a new finding. This has not been described previously. Procalcitonin is a recognized prognostic factor in pneumonia, but its implication in long-term prognosis is not easy to understand. Due to the multiple testing issues, this finding should be interpreted with caution and probably requires replication in a larger cohort.

Strengths of our study include a nonselected population representative of the global COPD population. We were able to take into account many important covariates, including clinical and biological evaluations at admission and at the end of the hospital stay. We believe that some of the analyzed covariates are readily available in daily practice. To limit the impact of missing variables, an imputation analysis was carried out and this confirmed the primary findings of the study.

A limitation of our study is its retrospective design with inherent bias, such as indication bias, not being excluded. This design also meant that several potential predictors were not sought out. These include previous admission for an exacerbation of COPD and the presence of functional impairment. Readmissions were only tracked at Geneva University Hospitals, but this represents a minor issue as it is the main and only public hospital in the region. Another limitation is the use of all cause mortality, as opposed to specific etiologies. These data were not systematically available. 


\section{Conclusion}

COPD remains of ominous prognosis, especially after exacerbation requiring hospitalization. Baseline pulmonary function remains the strongest predictor of mortality and new admission. Demographical factors, such as age and comorbidities, notably diabetes and cancer, are closely associated with the outcome of the patient. Respiratory rate at admission appears to be the most prognostic clinical parameter. A prospective validation is, however, still required to enable the identification of patients at higher risk of death or readmission.

\section{Disclosure}

The authors report no conflicts of interest in this work.

\section{References}

1. Mathers CD, Loncar D. Projections of global mortality and burden of disease from 2002 to 2030. PLoS Med. 2006;3(11):e442.

2. Vestbo J, Hurd SS, Agusti AG, et al. Global strategy for the diagnosis, management, and prevention of chronic obstructive pulmonary disease: GOLD executive summary. Am J Respir Crit Care Med. 2013;187(4): 347-365.

3. Burrows B, Earle RH. Course and prognosis of chronic obstructive lung disease. A prospective study of 200 patients. N Engl J Med. 1969; 280(8):397-404.

4. Miravitlles M, Guerrero T, Mayordomo C, Sanchez-Agudo L, Nicolau F, Segu JL. Factors associated with increased risk of exacerbation and hospital admission in a cohort of ambulatory COPD patients: a multiple logistic regression analysis. The EOLO Study Group. Respiration. 2000; 67(5):495-501.

5. Donaldson GC, Wilkinson TM, Hurst JR, Perera WR, Wedzicha JA. Exacerbations and time spent outdoors in chronic obstructive pulmonary disease. Am J Respir Crit Care Med. 2005;171(5):446-452.

6. Dijk WD, Bemt L, Haak-Rongen S, et al. Multidimensional prognostic indices for use in COPD patient care. A systematic review. Respir Res. 2011;12:151.

7. Connors AF Jr, Dawson NV, Thomas C, et al. Outcomes following acute exacerbation of severe chronic obstructive lung disease. The SUPPORT investigators (Study to Understand Prognoses and Preferences for Outcomes and Risks of Treatments). Am J Respir Crit Care Med. 1996; 154(4 pt 1):959-967.

8. Fruchter O, Yigla M. Predictors of long-term survival in elderly patients hospitalized for acute exacerbations of chronic obstructive pulmonary disease. Respirology. 2008;13(6):851-855.

9. Groenewegen KH, Schols AM, Wouters EF. Mortality and mortalityrelated factors after hospitalization for acute exacerbation of COPD. Chest. 2003;124(2):459-467.

10. Patil SP, Krishnan JA, Lechtzin N, Diette GB. In-hospital mortality following acute exacerbations of chronic obstructive pulmonary disease. Arch Intern Med. 2003;163(10):1180-1186.

11. Perera WR, Hurst JR, Wilkinson TM, et al. Inflammatory changes, recovery and recurrence at COPD exacerbation. Eur Respir J. 2007; 29(3):527-534.

12. Roche N, Zureik M, Soussan D, Neukirch F, Perrotin D; Urgence BPCO (COPD Emergency) Scientific Committee. Predictors of outcomes in COPD exacerbation cases presenting to the emergency department. Eur Respir J. 2008;32(4):953-961.

13. Steer J, Gibson J, Bourke SC. The DECAF score: predicting hospital mortality in exacerbations of chronic obstructive pulmonary disease. Thorax. 2012;67(11):970-976.

14. Singanayagam A, Schembri S, Chalmers JD. Predictors of mortality in hospitalized adults with acute exacerbation of chronic obstructive pulmonary disease. Ann Am Thorac Soc. 2013;10(2):81-89.
15. Steer J, Gibson GJ, Bourke SC. Predicting outcomes following hospitalization for acute exacerbations of COPD. QJM. 2010;103(11):817-829.

16. Burton A, Altman DG. Missing covariate data within cancer prognostic studies: a review of current reporting and proposed guidelines. Br JCancer. 2004;91(1):4-8

17. Marshall A, Altman DG, Royston P, Holder RL. Comparison of techniques for handling missing covariate data within prognostic modelling studies: a simulation study. BMC Med Res Methodol. 2010;10:7.

18. van Buuren S, Groothuis-Oudshoorn K, Robitzsch A, Vink G, Doove L, Jolani S [webpage on the Internet]. Multivariate Imputation by Chained Equations. 2015. Available from: https://cran.r-project.org/web/ packages/mice/index.html. Accessed December 16, 2016.

19. Burrows B, Bloom JW, Traver GA, Cline MG. The course and prognosis of different forms of chronic airways obstruction in a sample from the general population. $N$ Engl J Med. 1987;317(21):1309-1314.

20. Miravitlles M, Espinosa C, Fernandez-Laso E, Martos JA, Maldonado JA, Gallego M. Relationship between bacterial flora in sputum and functional impairment in patients with acute exacerbations of COPD. Study Group of Bacterial Infection in COPD. Chest. 1999;116(1): $40-46$.

21. Mannino DM, Thorn D, Swensen A, Holguin F. Prevalence and outcomes of diabetes, hypertension and cardiovascular disease in COPD. Eur Respir J. 2008;32(4):962-969.

22. Rana JS, Mittleman MA, Sheikh J, et al. Chronic obstructive pulmonary disease, asthma, and risk of type 2 diabetes in women. Diabetes Care. 2004;27(10):2478-2484.

23. Engstrom G, Janzon L. Risk of developing diabetes is inversely related to lung function: a population-based cohort study. Diabet Med. 2002; 19(2):167-170.

24. Ford ES, Mannino DM; National Health and Nutrition Examination Survey Epidemiologic Follow-up Study. Prospective association between lung function and the incidence of diabetes: findings from the National Health and Nutrition Examination Survey Epidemiologic Follow-up Study. Diabetes Care. 2004;27(12):2966-2970.

25. Agusti A, Barnes PJ. Update in chronic obstructive pulmonary disease 2011. Am J Respir Crit Care Med. 2012;185(11):1171-1176.

26. Anthonisen NR, Connett JE, Enright PL, Manfreda J; Lung Health Study Research Group. Hospitalizations and mortality in the Lung Health Study. Am J Respir Crit Care Med. 2002;166(3):333-339.

27. Piquet J, Chavaillon JM, David P, et al; French College of General Hospital Respiratory Physicians (CPHG). High-risk patients following hospitalisation for an acute exacerbation of COPD. Eur Respir J. 2013; 42(4):946-955.

28. Celli BR, Cote CG, Marin JM, et al. The body-mass index, airflow obstruction, dyspnea, and exercise capacity index in chronic obstructive pulmonary disease. $N$ Engl J Med. 2004;350(10):1005-1012.

29. Hasegawa W, Yamauchi Y, Yasunaga H, et al. Factors affecting mortality following emergency admission for chronic obstructive pulmonary disease. BMC Pulm Med. 2014;14:151.

30. Pauwels RA, Buist AS, Calverley PM, Jenkins CR, Hurd SS. Global strategy for the diagnosis, management, and prevention of chronic obstructive pulmonary disease. NHLBI/WHO Global Initiative for Chronic Obstructive Lung Disease (GOLD) Workshop summary. Am J Respir Crit Care Med. 2001;163(5):1256-1276.

31. Cretikos MA, Bellomo R, Hillman K, Chen J, Finfer S, Flabouris A. Respiratory rate: the neglected vital sign. Med J Aust. 2008;188(11):657-659.

32. Asiimwe AC, Brims FJ, Andrews NP, et al. Routine laboratory tests can predict in-hospital mortality in acute exacerbations of COPD. Lung. 2011;189(3):225-232.

33. Becker KL, Snider R, Nylen ES. Procalcitonin in sepsis and systemic inflammation: a harmful biomarker and a therapeutic target. $\mathrm{Br} J$ Pharmacol. 2010;159(2):253-264.

34. Stolz D, Christ-Crain M, Bingisser R, et al. Antibiotic treatment of exacerbations of COPD: a randomized, controlled trial comparing procalcitoninguidance with standard therapy. Chest. 2007;131(1):9-19.

35. Liu D, Su LX, Guan W, Xiao K, Xie LX. Prognostic value of procalcitonin in pneumonia: a systematic review and meta-analysis. Respirology. 2016;21(2):280-288. 
International Journal of COPD

\section{Publish your work in this journal}

The International Journal of COPD is an international, peer-reviewed journal of therapeutics and pharmacology focusing on concise rapid reporting of clinical studies and reviews in COPD. Special focus is given to the pathophysiological processes underlying the disease, intervention programs, patient focused education, and self management protocols

\section{Dovepress}

This journal is indexed on PubMed Central, MedLine and CAS. The manuscript management system is completely online and includes a very quick and fair peer-review system, which is all easy to use. Visit $\mathrm{http}: / / \mathrm{www}$.dovepress.com/testimonials.php to read real quotes from published authors.

Submit your manuscript here: http://www.dovepress.com/international-journal-of-chronic-obstructive-pulmonary-disease-journal 